\title{
Application of Dyeing Method in Preparation of Collagen Modified
}

\section{Cotton}

\author{
Xuemin $\mathrm{Hu}^{1, \text { a }}$ \\ ${ }^{1}$ School of Textile \& Garments, Hebei University of Science \& Technology, \\ Shijiazhuang, Hebei, China \\ ahuxuemin518@126.com
}

Keywords: Collagen modified cotton, Acid dyes, Reactive dyes, K/S Value

Abstract. By selectively oxidating the cotton, part of the alcoholic hydroxyl group is oxidized to an aldehyde group, then use cross-linking agents or glutaraldehyde to make it react with the amino on collagen protein to produce imide, thereby allow the collagen firmly bind with cotton fabirc to obtain cotton modified with collagen protein. The dyeing properties of the collagen modified cotton fabirc with acid dyes and reactive dyes were studied. Results shows that dyeing method in the characterization of the modification effect collagen modified cotton was effective. Compared with original cotton fabric, because of the introduction of collagen the $\mathrm{K} / \mathrm{S}$ value with acid dyes was significantly improved on collagen modified cotton and the $\mathrm{K} / \mathrm{S}$ value with reactive dyes was indecreased.

\section{Introduction}

Cotton is currently the most widely used natural cellulose fabirc material in textile industry because of their numerous advantages. It is pursued for its renewable, biodegradable, low cost, rich resource and other advantages. [1,2] How to modify the cotton fabirc and characterize of the modification have become the hot topics.Collagen which is containing a large number of hydrophilic groups, with good moisture absorption has a good skin-friendly. The deeply researches on the preparation of modified cotton with collagen were carried out. The effect of dyeing method in the characterization of the collagen modified cotton was applied to the study. Compared with original cotton fabric, the $\mathrm{K} / \mathrm{S}$ value with acid dyes was significantly improved on collagen modified cotton, and the $\mathrm{K} / \mathrm{S}$ value with reactive dyes was decreased.

\section{Theories and Solutions}

The theories of oxidization cotton with oxidant. Cotton is the most important cellulose fabirc. Cellulose is a polyhydroxy compound. Treatment of cellulose fabirc in acidic, neutral or alkaline solutions with oxidizing agents leads to chemical attack, almost invariably and loss of tensile strength. The products of oxidation may retain the original fibrous form but may, depending on the reagent and vigor of the attack, be a friable powder. The mechanism of reaction of periodate with $\alpha$-glycols consists of a rapid reaction to form univalent anionic which an easily dehydrate to give second univalent ester. This ester decomposes slowly giving the aldehyde groups. Cellulose has a structure of the $\alpha$-glycols type and oxidation under sodium periodate can produce the two aldehyde groups expected. Reaction equations are as follows: 


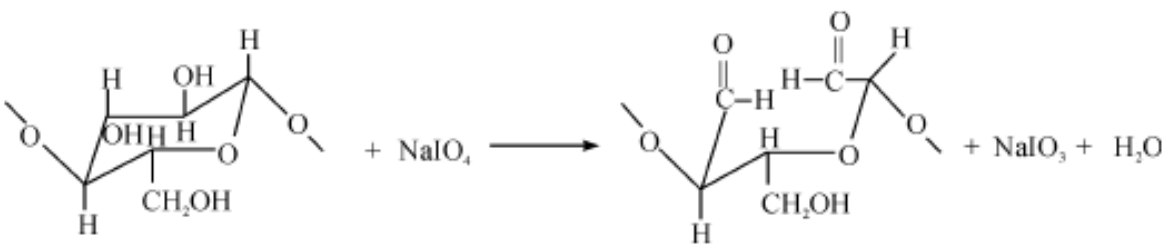

The principle of collagen modified cotton. Oxycellulose has many reactive aldehyde groups which can react with amino on the collagen molecule. In order to strengthen this binding capacity, generally added dialdehyde compound as a crosslinking agent. The dialdehyde compound has two reactive aldehyde groups. All the aldehyde groups react with the amino group on the collagen to form Schiff bonds. [3] The cross-linking between collagen and cotton is formed without damaging the physical and mechanical properties of cotton which can effectively improve the wash fastness and binding fastness of cellulose fabircs and collagen. The reaction mechanism is as follows:

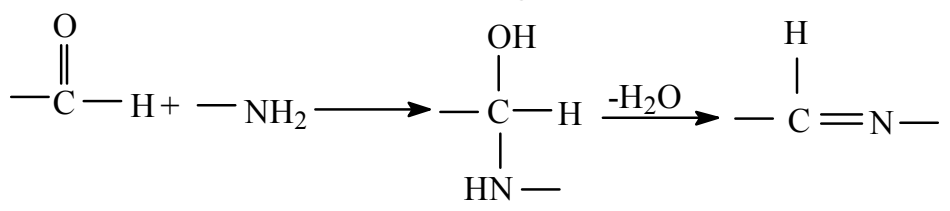

Dyeing mechanism of collagen modified cotton with reactive dyes. Reactive dyes is the main dyes in printing and dyeing of cellulosic fabircs. [4] In a certain alkaline and temperature condition, the active groups of reactive dyes should be react with the negative ions of the cellulose by covalent bonding.[5] The reaction mechanism is as follows:

$$
\mathrm{CeII}-\mathrm{OH} \stackrel{\mathrm{OH}^{-}}{\longrightarrow} \mathrm{CeIIO}
$$

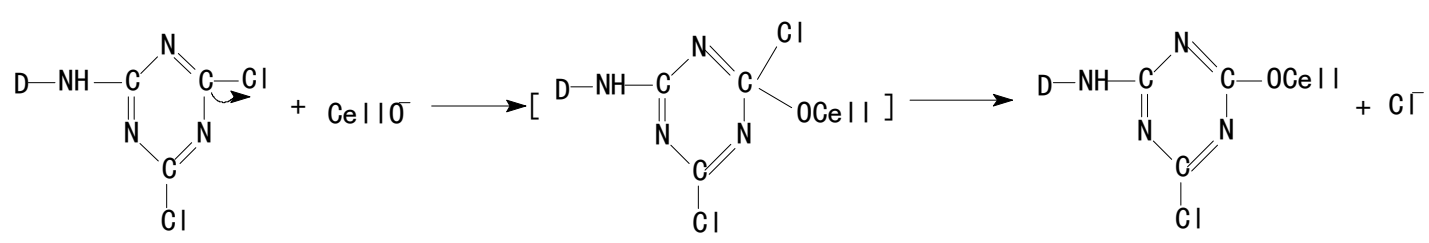

Dyeing formulation and technology of reactive dyes. Concentration of reactive dyes $2 \%$ (owf), sodium chloride $40 \mathrm{~g} / \mathrm{L}$, sodium carbonate solution $15 \mathrm{~g} / \mathrm{L}$, ratio of water and fabirc was 30:1. Dyeing $30 \mathrm{~min}$ at temperature $40^{\circ} \mathrm{C}$ and fixation $40 \mathrm{~min}$ at temperature $60^{\circ} \mathrm{C}$. The soaping technology is time $40 \mathrm{~min}$, temperature $60^{\circ} \mathrm{C}$, ratio of water and fabirc was $30: 1$, concentration of soap $1 \mathrm{~g} / \mathrm{L}$.

Dyeing mechanism of collagen modified cotton with acid dyes. After sodium periodate oxidation of cotton fabric the hydroxyl groups changed into aldehyde groups. The aldehyde groups react with the collagen covered on the modified fabirc. The dyeing effect of acid dye is good on protein fabircs, but acid dyes are not used in the dyeing of cotton fabircs. Because collagen is the protein, acid dyes have good dyeing ability on the collagen. According to this principle, the number of collagen on the modified fabirc is characterized by the amount of acid dyes existing on the modified fabirc in the experiments. Higher dyeing percentage of acid dyes on the modified fabirc means that the modification result is better, On the contrary, the worse. The dyeing reaction mechanism is as follows: 


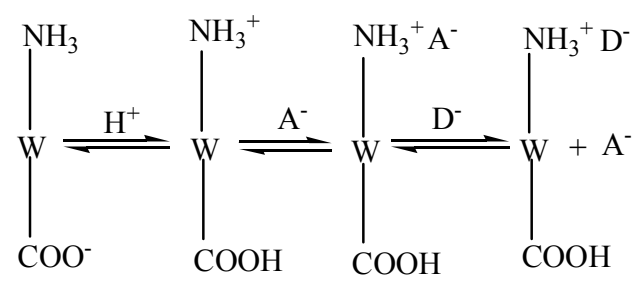

Dyeing formulation and technology of acid dyes. Concentration of acid dyes $2 \%(\mathrm{owf}), \mathrm{pH} 5-6$, Sodium sulphate $6 \%$, ratio of water and fabirc was 100:1. Dyeing $70 \mathrm{~min}$ at temperature $80^{\circ} \mathrm{C}$.

Testing solution of dyeing depth with reactive dyes and acid dyes. $\mathrm{K} / \mathrm{S}$ values commonly used in measuring surface color depth of fabric. A linear relationship exists between the K/S value and the dye concentration on the textile. It is an important index of product surface color shades. K/S values are generally expressed in different samples of the apparent color depth, the greater the K/S value, the darker the color. The modified cotton fabirc was dyed by the specified process, and the $\mathrm{K} / \mathrm{S}$ value of the modified cotton fabric were measured.

Experiment solutions. Weighing out certain cotton fabric and put it into concentration of sodium periodate $0.6 \mathrm{~g} / \mathrm{L}$, time $2.5 \mathrm{~h}$, temperature $40^{\circ} \mathrm{C}$, ratio of water and cotton fabric was $30: 1$. Oxidation is occurred at the conditions. Put the oxidized cotton fabric into concentrations of collagen solution $5 \%$, glutaraldehyde concentration $6 \%$, liquor retention $70 \%$, reaction at $30^{\circ} \mathrm{C}$ for $80 \mathrm{~min}$. At last dyeing the somples with reactive dyes and acid dyes and measuring the $\mathrm{K} / \mathrm{S}$ value.

\section{Results and discussions}

K/S value after soaping and colorfastness to washing with reactive dyes on collagen modified cotton. The K/S value after soaping and color fastness to washing of collagen modified cotton dyed with reactive dyes were determined. The datas are shown in Table 1.

Table $1 \mathrm{~K} / \mathrm{S}$ value after soaping and colorfastness to washing with reactive dyes on collagen modified cotton

\begin{tabular}{|l|c|c|c|}
\hline \multirow{2}{*}{ reactive dyes } & K/S value after soaping & \multicolumn{2}{|c|}{$\begin{array}{c}\text { color fastness to washing/grade } \\
\text { discoloration }\end{array}$} \\
\hline Red 4RD & 22.71 & 4 & $3-4$ \\
\hline Yellow 3RD & 23.16 & 4 & 4 \\
\hline Blue & 26.79 & 4 & 4 \\
\hline
\end{tabular}

K/S value after dyeing and colorfastness to washing with acid dyes on collagen modified cotton. The K/S value after dyeing and color fastness to washing of collagen modified cotton dyed with acid dyes were determined. The datas are shown in Table 2. The dates of K/S value and colorfastness to washing with acid dyes and reactive dyes on cotton are shown in Table 3.

Table $2 \mathrm{~K} / \mathrm{S}$ value and colorfastness to washing with acid dyes on collagen modified cotton

\begin{tabular}{|l|c|c|c|}
\hline \multirow{2}{*}{ acid dyes } & \multirow{2}{*}{ K/S value after dyeing } & \multicolumn{2}{|c|}{$\begin{array}{c}\text { color fastness to washing/grade } \\
\text { discoloration }\end{array}$} \\
\hline Ciba Pula red B & 7.13 & 3 & 3 \\
\hline Ciba Pula yellow 4G & 7.46 & 3 & 3 \\
\hline Ciba Pula blue RAWL & 6.09 & $2-3$ & 3 \\
\hline
\end{tabular}


Table $3 \mathrm{~K} / \mathrm{S}$ value and colorfastness to washing with reactive dyes and acid dyes on cotton

\begin{tabular}{|l|c|c|c|c|}
\hline acid dyes & K/S value after dyeing & K/S value after soaping & \multicolumn{2}{|c|}{$\begin{array}{c}\text { color fastness to washing/grade } \\
\text { discoloration }\end{array}$} \\
\hline reactive dyes & 30.47 & 29.73 & 4 & 4 \\
\hline acid dyes & 2.45 & - & 2 & $2-3$ \\
\hline
\end{tabular}

Compared with cotton fabric, the $\mathrm{K} / \mathrm{S}$ value of the collagen modified cotton fabirc dyed with reactive dyes is decreased. The experimental results indicate that the hydroxyl content of the fabirc decreased because the hydroxyl in the contton fabirc is oxidized. That is, little active groups of cellulose can react with the reactive dyes. The dyeing properties of reactive dyes on the collagen modified cotton fabirc are falling.

On the contrary, the $\mathrm{K} / \mathrm{S}$ value of acid dyes on the modified fabirc was increased and the dyeing properties were improved. Acid dyes is mainly used in the dyeing of wool, silk and other protein fabirc and polyamide fabirc. Because the collagen modified cotton rich in collagen the K/S value of acid dyes is more than cotton.

\section{Conclusions}

Collagen can be used to modify the cotton fabric by oxidation-first and then crosslinking. Dyeing methods with acid dyes and reacive dyes are effective in the characterization of the modification effect collagen modified cotton. the $\mathrm{K} / \mathrm{S}$ value with acid dyes was significantly improved on collagen modified cotton and the K/S value with reactive dyes was indecreased.

\section{References}

[1] Rahn K, Heinze. Cellulosic polymers by subsequent modification of 2, 3-dialdehyde cellulose. Cellulose Chemistry and Technology, Vol. 32 (1998), p. 173

[2] Mu Yao, in: Textile materials, edited by China textile publication, Beijing(1990)in press.

[3] Lili Wang, Wei Ma, Shufen Zhang, Xiaoxu Teng, Jinzong Yang. Preparation of cationic cotton with two-bath pad-bake process and its application in salt-free dyeing. Carbohydrate Polymers, Vol. 1 (2009), P.783

[4] J. Koh et al. Reactive dyeing properties of novel regenerated cellulosic fibers. Dyes and Pigments , 64(2005), p.9

[5] S.J. Tang, Y. Zhang and X.F. Song, Dyestuffs and Coloration .43, 3(2006) (In Chinese) 